\title{
СОЦИАЛЬНО-ЭКОНОМИЧЕСКИЕ ПРЕДПОСЫЛКИ РАЗВИТИЯ КОММЕРЧЕСКОГО СЕКТОРА ЛОГОПЕДИЧЕСКИХ УСЛУГ (НА ПРИМЕРЕ КУРСКОЙ ОБЛАСТИ)
}

\author{
(C) 2020 Евдокимова Лариса Александровна \\ кандидат педагогических наук \\ Курский институт развития, Россия, Курск \\ E-mail:1lotos1953@mail.ru
}

В статье рассматриваются социально-экономические предпосылки развития коммерческого сектора логопедических услуг на примере Курской области, что в условиях высокой частоты наличия у детей речевых отклонений и несовершенства бюджетной системы дошкольного образования, приобретает особую востребованность. Исследование регионального рынка логопедических услуг показало большую вариативность существующих форм и стоимости оказываемых на платной основе услуг по коррекции речевых дефектов у детей.

Ключевые слова: Курская область, педагогика, логопедия, дефекты речи, платные услуги, рынок логопедических услуг.

Логопедическая помощь сегодня является одним из значимых направлений медикопедагогической помощи, оказываемой детям. Это связано с тем фактом, что статистика наличия речевых нарушений у детей является крайне высокой, а перечень и разнообразие возникающих отклонений не являются исчерпывающими. Роль логопедической помощи огромна, поскольку она способствует правильному формированию речевого аппарата у детей и произношению звуков. Отсутствие своевременного должного внимания к речевым дефектам в детском возрасте может привести к переходу данных проблем во взрослую жизнь и формированию целого ряда комплексов [1].

Поскольку львиная доля всех речевых дефектов приходится именно на детский возраст и период становления речевого аппарата, то во многих учреждениях дошкольного и начального общего образования страны в штате сотрудников присутствует логопед, который оказывает квалифицированную помощь детям, имеющим соответствующие речевые отклонения. Однако оптимизация коснулась не только кадров в системе здравоохранения, но и в педагогической среде, в результате чего в стране снизилась обеспеченность детского населения логопедами, а оставшиеся мощности просто физически не способны уделить должного внимания всем детям с речевыми нарушениями. Все эти условия сформировали благоприятные предпосылки для развития коммерческого сегмента логопедических услуг и появления большого числа частных детских садов, развивающих речевых центров, чем и обусловлена актуальность исследования [2].

С использованием статистических данных [3], в ходе исследования проведен анализ социально-экономических факторов развития логопедической помощи в Курской области на основе динамики численности и обеспеченности населения региона учителями-логопедами, а также основных экономических показателей региона в период 2013-2018 гг., выявлены сложившиеся тенденции и факторы, их сформировавшие.

Установлено, что общая численность логопедов в области имеет достаточно устойчивую тенденцию к росту. Если в 2013 году всего насчитывалось только 234 учителя-логопеда, то уже в 2014 году данное значение возросло до 251 чел., а к 2016 году - до 274 чел. Начиная с 2016 года темпы прирост численности логопедов в Курской области снизились, в результате чего к 2018 году рассматриваемый показатель достиг значения 294 чел. При этом, прирост численности за 6 рассматриваемых лет составил 60 чел. или $25,6 \%$.

Логопедическая помощь является составной частью медицинской реабилитации и зачастую может оказываться не только в профильных учреждениях, но и в рамках медицинских организаций. В соответствии с утвержденным Министерством Здравоохранения РФ Порядком организации медицинской реабилитации [4], регулирующим вопросы организации ме- 
дицинской реабилитации взрослого и детского населения на основе комплексного применения природных лечебных факторов, лекарственной, немедикаментозной терапии и других методов, рекомендуемый штатный норматив логопедов составляет 1,0 в расчете на 3,5 тыс. населения. В ходе исследования было определено, сколько в среднем логопедов приходится на 3,5 тыс. населения Курской области. В результате выявлена положительная тенденция к росту уровня обеспеченности логопедами, однако во всем исследуемом периоде данный показатель составляет менее 1,0. Если в 2013 году на 3,5 тыс. курян приходилось 0,73 логопедов, то к 2018 году данное значение возросло до 0,93 , что несколько ниже рекомендуемого значения (рисунок 1).

Несмотря на относительно низкий уровень обеспеченности населения Курской области логопедами, коммерческий рынок логопедических услуг сегодня активно развивается в регионе. Это связано с широким распространением различных дефектов речи, в первую очередь, у детей, требующих своевременной коррекции. Поэтому в рамках исследования проведена оценка развития коммерческого сегмента рынка логопедических услуг Курской области по состоянию на январь 2020 года. Для целей исследования было отобрано 15 основных специализированных детских учреждений области, в которых оказывается логопедическая помощь, и проведено сравнение стоимости одного индивидуального занятия с врачом логопедом в них. В рамках логического анализа сравниваемые учреждения были сгруппированы по стоимостному признаку на 3 группы.
Установлено, что в регионе существует значительная ценовая дифференциация на данную услугу, поскольку цена варьирует в пределах 300-800 руб. В результате, средняя стоимость занятия с логопедом в Курской области составляет 490 руб. По результатам группировки в первую группу вошли 5 учреждений, в которых стоимость одного занятия с логопедом ниже среднего уровня и составляет 300-400 рублей. При этом, цена данной услуги в трех из пяти организаций составляет 300 рублей, что на 39\% ниже средней по региону, а еще в $2-\mathrm{x}-400$ рублей, что на $18,4 \%$ ниже среднего уровня. Во вторую группу, согласно проведенной группировке, вошло 6 организаций Курской области, в которых средняя стоимость индивидуального занятия с логопедом на $2 \%$ выше среднего и составляет 500 рублей. Третья группа включает еще 4 учреждения региона, цены в которых дифференцированы значительно и являются относительно высокими. Так, в Речевом центре «Демосфен» одно занятие с логопедом стоит 550 руб., в Центре развития и коррекции «Время детям» -600 руб., Центре педиатрии «Живели» - 700 руб., а в Центре развития и коррекции «Дети-Ангелы» -800 руб. В результате, самая высокая стоимость одного занятия с логопедом превышает среднюю по региону цену более чем на $63 \%$.

Стоит отметить, что большинство из рассматриваемых детских центров в регионе являются мультидисциплинарными и направлены на общее всестороннее развитие детей, а именно - дошкольную подготовку и развитие. Логопедические услуги являются одним из элементов развития детей и носят побочный характер, по-

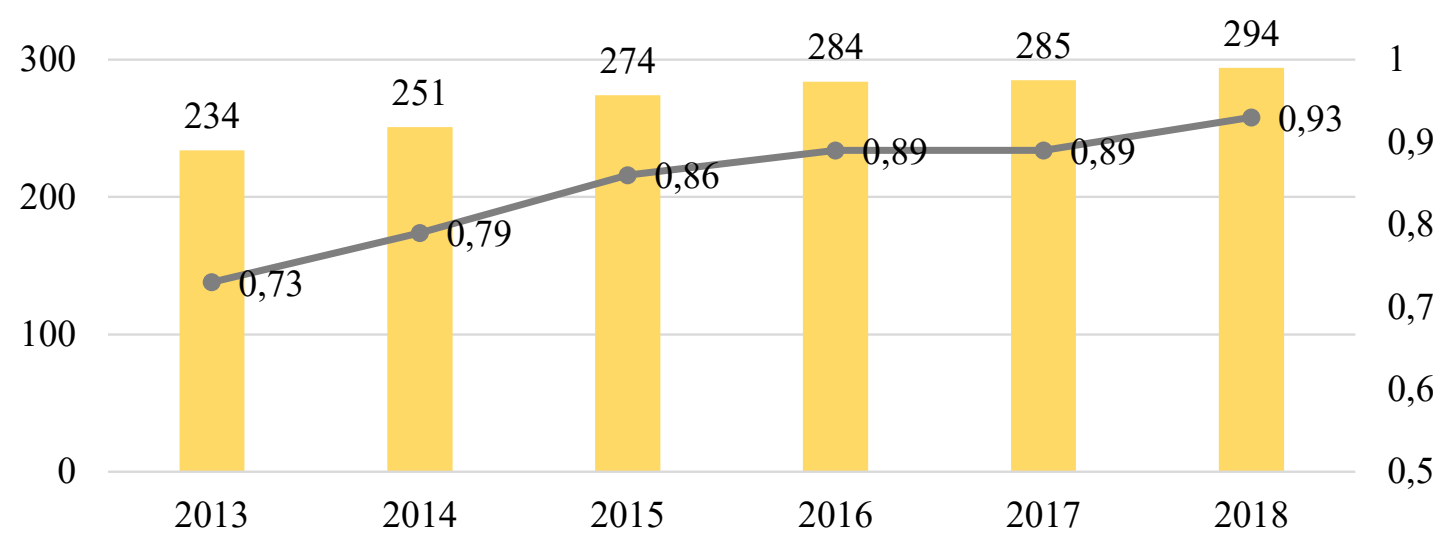

Численность логопедов в Курской области, чел.

- Обеспеченность населения Курской области логопедами, чел на 3,5 тыс. населения

Рисунок 1. Динамика численности логопедов в Курской области и обеспеченности населения ими в 2013-2018 гг. 
скольку потребность в логопедической помощи возникает не у каждого ребенка. Рассматривая логопедию как самостоятельную деятельность, можно отметить, что лишь 5 из 15 представленных организаций (Логопедический центр «Азбука звуков», Логопедический центр «Доктор звуков», Центр развития речи «Логовита», Логопедический кабинет «ЛогоМир», Речевой центр «Демосфен») являются узкоспециализированными и направлены исключительно на оказание логопедических услуг (таблица 1 ).

Исследование рынка логопедических услуг Курской области показало, что помимо целого ряда специализированных детских центров, в регионе также существует огромное количество частных логопедов, предлагающих свои услуги через интернет-ресурсы. Здесь также можно выделить значительный разброс цен, однако минимальная стоимость, как и в специализированных центрах, составляет 300 рублей за 30 мин. занятия. Верхний стоимостной предел для частных логопедов в Курской области был определен в размере 1000 руб., что выше стоимости аналогичных услуг в самом дорогом из представленных центров детского развития. Положительными аспектами в пользу выбора частного логопеда является возможность проведения занятий на дому, однако, в то же время, достоверно установить компетентность педагога и качество предоставляемых им услуг проблематично. При выборе логопедических услуг в специализированных детских центрах существует большая защищенность клиентов как потребителей, а за компетентность и профессионализм сотрудников отвечает руководство.

В большинстве бюджетных дошкольных образовательных учреждений (детских садах) области в штате есть логопед, а также зачастую формируются профильные логопедические группы для детей с речевыми дефектами. Также

Таблица 1. Сравнительный анализ стоимости одного индивидуального занятия с логопедом в различных профильных организациях Курской области в январе 2020 года

\begin{tabular}{|c|c|c|c|c|}
\hline № & $\begin{array}{c}\text { Наименование } \\
\text { организации }\end{array}$ & $\begin{array}{c}\text { Адрес } \\
\text { местонахождения в } \\
\text { г. Курске }\end{array}$ & $\begin{array}{l}\text { Стоимость } \\
\text { одного заня- } \\
\text { тия с логопе- } \\
\text { дом, руб. }\end{array}$ & $\begin{array}{c}\text { Отклонение } \\
\text { от средней } \\
\text { цены,\% }\end{array}$ \\
\hline \multirow{5}{*}{1} & Детский центр «Лесенка» & Пр-т Кулакова 9, кв.1 & 300 & $-38,8$ \\
\hline & $\begin{array}{l}\text { Центр по уходу и присмотру за детьми } \\
\text { «Хоровод» }\end{array}$ & Пр-т В. Клыкова 38 & 300 & $-38,8$ \\
\hline & $\begin{array}{l}\text { Центр тестирования и развития личности } \\
\text { «О`Гений» }\end{array}$ & Ул. Почтовая 12 & 300 & $-38,8$ \\
\hline & Репетиторский центр «Юджин» & $\begin{array}{l}\text { Ул. Радищева 79 А } \\
\text { Ул. Павлуновского } 3 \\
\text { Магистральный пр-д } 3 \text { A }\end{array}$ & 400 & $-18,4$ \\
\hline & Логопедический центр «Азбука звуков» & ул. Пигорева 18 & 400 & $-18,4$ \\
\hline \multirow{6}{*}{2} & Логопедический центр «Доктор звуков» & $\begin{array}{l}\text { Пр-т В. Клыкова, д. 39-А } \\
\text { Ул. Радищева, д. } 110\end{array}$ & 500 & 2,0 \\
\hline & Центр развития речи «Логовита» & Ул. К. Маркса 62/21 & 500 & 2,0 \\
\hline & Логопедический кабинет «ЛогоМир» & Пр-т В. Клыкова, д. 1А & 500 & 2,0 \\
\hline & $\begin{array}{l}\text { Мультидисциплинарный центр развития } \\
\text { «Меридиан» }\end{array}$ & Ул. Карла Либкнехта, 22 & 500 & 2,0 \\
\hline & $\begin{array}{l}\text { Центр развития личности «ПРОФИ } \\
\text { малыш» }\end{array}$ & Театральный пр-д. 1 & 500 & 2,0 \\
\hline & Репетиторский центр «Вектор Удачи» & $\begin{array}{l}\text { ул. Радищева д. } 28 \\
\text { пр-т Дериглазова, д. 53, кв.2 }\end{array}$ & 500 & 2,0 \\
\hline \multirow{4}{*}{3} & Речевой центр «Демосфен» & Ул. Садовая, 5 & 550 & 12,2 \\
\hline & $\begin{array}{l}\text { Центр развития и коррекции «Время } \\
\text { детям» }\end{array}$ & 2-й Запольный пер., д. 30 & 600 & 22,4 \\
\hline & Центр педиатрии «Живели» & ул. Красной Армии 100, & 700 & 42,9 \\
\hline & $\begin{array}{l}\text { Центр развития и коррекции «Дети- } \\
\text { Ангелы» }\end{array}$ & г. Курск ул. Почтовая 12 & 800 & 63,3 \\
\hline \multicolumn{3}{|c|}{ Средняя стоимость услуги в Курской области, руб. } & \multicolumn{2}{|c|}{490} \\
\hline
\end{tabular}


педагог-логопед в большинстве случаев имеется и в системе начального общего образования. Однако, ситуация складывается таким образом, что нередко молодые родители относятся с большим недоверием к штатным логопедам и системе дошкольного и начального образования детей, предлагаемой в рамках бюджетных учреждений, предпочитая посещать частные центры развития и коррекции за отдельную плату. Все это способствует тому, что сегодня логопедия является одним из динамично развивающихся направлений, формирующих своего рода рынок данного вида услуг.

Вместе с тем, основным фактором развития регионального рынка платных услуг, в том числе и логопедических, является общий уровень экономического развития субъекта и размер доходов населения. В результате оценки основных экономических показателей Курской области в период 2013-2018 гг. были выявлены положительные тенденции. Так, за последние 6 лет размер ВРП региона в расчете на душу населения возрос более чем на $46 \%$, достигнув 355 тыс. руб. в сравнении с 242,6 тыс. руб. в 2013 году. При этом размер среднедушевых доходов населения также возрос, но в наименьшей степени (38,8\% за 6 лет), достигнув 27 тыс. рублей к 2018 году. Средняя заработная плата в регионе также растет: если на начало рассматриваемого периода средний уровень оплаты труда составлял 21,2 тыс. руб., то на конец 2018 года данный показатель возрос до 29,9 тыс. руб., что характеризует прирост на уровне $41 \%$ за 6 лет. Улучшение ситуации привело к росту объема инвестиций в основной капитал, отражающих инвестиционную активность в регионе и темпы развития бизнеса, которые имеет устойчивую тенденцию к росту высокими темпами: за 6 лет общий прирост составил $67,6 \%$, а абсолютное значение показате- ля достигло 119,9 млрд. руб. в сравнении с 71,5 млрд. руб. в базисном году (таблица 2).

Полученные результаты свидетельствуют о том, что в последние годы экономика региона оживает. Если в период после кризиса 2014 года значительный скачок стоимостных показателей в наибольшей степени был обусловлен инфляционными процессами и падением курса рубля, то сегодня, на этапе относительной экономической стабильности, рост в наибольшей степени обусловлен именно улучшением экономических процессов. Стоит отметить, что, несмотря на возникшие в последние годы экономические трудности, коммерческому сегменту рынка медицинских и образовательных удалось сохранить относительную стабильность, что подтверждает их значимость в системе ценностей населения. Сегодня, на фоне улучшения общей экономической обстановки, потребление населением платных услуг, в том числе и образовательных, неуклонно растет.

По итогам проведенного исследования было установлено, что сегодня в Курской области отмечается рост численности логопедов и уровня обеспеченности населения ими. В результате, по состоянию на 2018 году в регионе 294 педагогалогопеда, а на 3,5 тыс. населения области приходится менее 1 логопеда, что несколько ниже рекомендуемого Минздравом уровня. Современные рыночные условия развития экономики формируют широкое развитие и популяризацию платного комплекса услуг, в том числе в сфере логопедии. Исследование регионального рынка логопедических услуг показало большую вариативность существующих форм и стоимости оказываемых на платной основе услуг по коррекции речевых дефектов. Так, сегодня в Курской области насчитывается более 30 различных центров развития детей и несколько

Таблица 2. Динамика основных экономических показателей Курской области в 2013-2018 гг.

\begin{tabular}{|c|c|c|c|c|c|c|c|}
\hline \multirow[b]{2}{*}{ Показатель } & \multicolumn{6}{|c|}{ Значение } & \multirow{2}{*}{$\begin{array}{c}\text { Изме- } \\
\text { нение в } \\
2018 \text { г. к } \\
2014 \text { г., \% }\end{array}$} \\
\hline & 2013 & 2014 & 2015 & 2016 & 2017 & 2018 & \\
\hline ВРП на душу населения, тыс. руб. & 242,6 & 266,8 & 301,2 & 323,1 & 346,3 & 355,0 & 46,3 \\
\hline $\begin{array}{l}\text { Среднедушевые денежные доходы } \\
\text { населения, тыс. руб. }\end{array}$ & 19,4 & 21,9 & 25,3 & 25,4 & 26,0 & 27,0 & 38,8 \\
\hline $\begin{array}{l}\text { Среднемесячная номинальная } \\
\text { начисленная заработная плата, } \\
\text { тыс. руб. }\end{array}$ & 21,2 & 23,1 & 23,9 & 25,3 & 27,3 & 29,9 & 41,0 \\
\hline $\begin{array}{l}\text { Инвестиции в основной капитал, } \\
\text { млрд. руб. }\end{array}$ & 71,5 & 73,7 & 73,7 & 93,7 & 100,9 & 119,9 & 67,6 \\
\hline
\end{tabular}


десятков частных логопедов, стоимость одного индивидуального занятия в которых варьирует в пределах 300-1000 рублей. Наличие достаточного количества игроков на рынке и значительный ценовой диапазон, позволяет говорить о высокой конкуренции на рынке логопедических услуг Курской области. При этом, некоторые организации предпочитают делать акцент на низкой стоимости и, как следствие, доступности данных услуг для широких слоев населения, другие же придерживаются политики высоких цен, подчеркивая свою исключительность на данном рынке.

В результате, несмотря на значимость в развитии рынка логопедических услуг экономической составляющей, выражающейся в небольшом повышении благосостояния населения региона в последние годы, основной формирующей предпосылкой является именно социальная компонента. Ситуация складывается таким образом, что качество образовательных услуг, как в дошкольных учреждениях, так и в учреждениях общего образования, снижается, что обусловлено не только ухудшением уровня подготовки специалистов в сфере педагогики, но и с несовершенством условий их труда и заработной платы, что формирует низкую мотивацию для достижения конечного результата. Работа с детьми является «ювелирной», а коррекция речевых дефектов - сложным многоаспектным процессом, требующим высокую отдачу, что в условиях бюджетных учреждений образования практически невозможно. Все это формирует значительное недоверие со стороны родителей к тем образовательным услугам, которые предоставляются бюджетными организациями. Поскольку процесс развития в детском возрасте является важным этап на пути становления человека, то родители предпочитают пользоваться услугами частных развивающих центров, осуществляя своего рода инвестиции в человеческий капитал.

\section{Библиографический список}

1. Саблева А.С. Речевой дефект в контексте социально-коммуникативного развития ребенка // Современная наука: актуальные проблемы теории и практики. Серия: Гуманитарные науки. 2019. № 8. С. 89-93.

2. Гудина Т.В., Денисова О.А., Казанская В.Л. Особенности образовательных запросов родителей в сфере дополнительного образования в дошкольном образовательном учреждении комбинированного вида // Вестник Череповецкого государственного университета. 2019. № 1 (88). С. 163-174.

3. Статистический ежегодник Курской области. 2019: Стат.сб./Курскстат.- Курск, 2019-444 с.

4. Приказ Министерства здравоохранения РФ от 29 декабря 2012 г. N1705н «О Порядке организации медицинской реабилитации» [Электронный ресурс].- Режим доступа: https://base.garant.ru/70330294/ (Дата обращения 23.01.2020 г.). 